\title{
REVERSAL OF SEVERE SPECT ASYMMETRY AFTER VENOUS EXTRA-INTRACRANIAL HIGH FLOW BYPASS IN A PATIENT SUBMITTED TO THERAPEUTIC INTERNAL CAROTID OCCLUSION
}

\section{Case report}

\author{
Jorge Marcondes', Antônio Aversa', Marcio Peçanha, \\ Flávio Domingues ${ }^{3}$, Fernanda Nascimento ${ }^{3}$, Charles Andrét, \\ Gabriel Freitas ${ }^{5}$, Feliciano Azevedo ${ }^{6}$, Maria Exposito ${ }^{7}$
}

\begin{abstract}
Therapeutic occlusion of the internal carotid artery is the main option for the treatment of the symptomatic intracavernous internal carotid artery aneurysms, but the issue of the best way of doing the balloon test occlusion (BTO) regarding prediction of future ischemic events remains debatable. Single photon emission computerized tomography (SPECT) has been offered as one of the best option of monitoring regional cerebral blood flow (rCBF) during the BTO, where severe asymmetry is predictive of delayed ischemia. We describe a case of important SPECT asymmetry during BTO clinically negative and its complete reversal with carotid occlusion after extra-intracranial bypass with high flow safenous vein bypass between the cervical carotid artery and the middle cerebral artery.
\end{abstract}

KEY WORDS: giant intracavernous aneurysm, cerebral revascularization, carotid artery occlusion, saphenous vein graft, SPECT.

\begin{abstract}
Reversão de importante assimetria ao SPECT após bypass venoso de alto fluxo extra-intracraniano em paciente submetido a oclusão terapêutica da carótida interna: relato de caso

RESUMO - Oclusão terapêutica carotídea ainda é a principal escolha para o tratamento dos aneurismas sintomáticos da artéria carótida interna ao nível do seio cavernoso. Existem controvérsias em relação à obtenção de testes com maior valor preditivo em relação à complicações isquêmicas futuras durante a realização do teste de oclusão carotídeo por balão. A tomografia computorizada de emissão de fóton único (SPECT) tem sido defendida como uma opção para a melhor avaliação do fluxo sanguíneo regional cerebral, onde evidente assimetria é indicativa de isquemia tardia. Descrevemos um caso de importante assimetria ao SPECT durante o teste clinicamente negativo e sua reversão completa após anastomose extra-intracraniana com interposição de veia safena magna (alto fluxo) entre a artéria carótida cervical e a artéria cerebral média.
\end{abstract}

PALAVRAS-CHAVE: aneurisma gigante intracavernoso, revascularização cerebral, anastomose vascular, fluxo sanguíneo cerebral, SPECT.

Therapeutic internal carotid occlusion remains as strategic option for the treatment of complex symptomatic aneurysms of the cavernous and petrous segments of the internal carotid artery (ICA) or neck and cranial base tumors encasing the carotid artery'. It has a central role in the management of intracaver- nous carotid aneurysms that presents with progressive ophthalmoplegia, documented enlargement on image tests, subaracnoid hemorrhage, epistaxis or intolerable facial pain. Careful analysis of the potential contraindications of carotid occlusion, however, should be considered. Absolute contraindication are

The Neurovascular Group of the Hospital Universitário Clementino Fraga Filho, Universidade Federal do Rio de Janeiro (HUCFF-UFRJ), Rio de Janeiro RJ, Brazil: 'Professor Adjunto e Chefe do Serviço de Neurocirurgia (SNC); ${ }^{2}$ Diretor do Setor de Base do Crânio, SNC; ${ }^{3}$ Residente do SNC; ${ }^{4}$ Professor Adjunto e Diretor do Setor Cerebrovascular do Serviço de Neurologia (SN); ${ }^{5}$ Mestrando do SN; ${ }^{6}$ Professor Assistente e Chefe do Setor Intervencionista do Serviço de Radiodiagnóstico; ${ }^{7}$ Professora Adjunta do Departamento de Radiologia do Serviço de Medicina Nuclear.

Received 15 February 2001, received in final form 16 May 2001. Accepted 24 May 2001.

Dr. Jorge Marcondes - Serviço de Neurocirurgia, Hospital Universitário Clementino Fraga Filho - Av. Brigadeiro Trompowsky s/n 22295-900 Rio de Janeiro RJ - Brasil.E-mail: jmarcondes@hucff.ufrj.br 


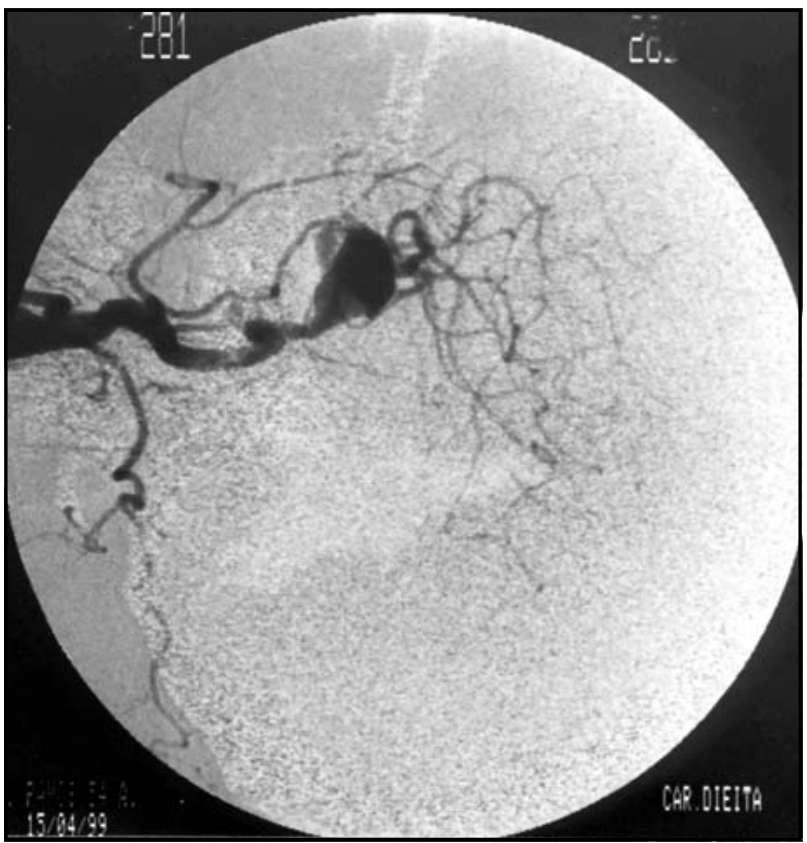

Fig 1. Digital subtraction angiography showing a giant aneurysm with its origin in the right horizontal segment of the cavernous carotid artery.

the situations that predict major risk for ischemic events due to inadequate cerebral blood flow (CBF) reserve, as severe contralateral carotid stenosis, cardiac failure, presence of vasospasm, angiographic evidence of absent or insufficient intracranial collaterals $^{2}$. Since the balloon test occlusion became the gold standard for the assessment of the carotid hemodinamic reserve, it has been enhanced in its preditive value for cerebral ischemia by means of adjunctive measurements. Standard et al. ${ }^{3}$ introduced the hypotensive challenge, using an intravenous infusion of nitroprusside to reduce the systolic blood pressure to $70 \%$ of the baseline (extending the occlusion time for extra 15 minutes - total of 30 minutes of ballon test occlusion (BTO)). They reported an increase in $20 \%$ of patients developing deficits when hypotension was added to the test.

Qualitative (SPECT) and quantitative (xenon-CT $\mathrm{CBF}$ ) analysis during test occlusion were introduced to help define the subgroup of patients at risk for cerebral ischemia even after successful clinical testing. Severe asymetry on the SPECT has been suggested as predictive of poor hemodynamic reserve ${ }^{4}$ as well as CBF values below $30 \mathrm{ml} / 100 \mathrm{~g} / \mathrm{min}$ on the xenonCT test ${ }^{5}$. In those patients that failed the BTO test, an EC-IC bypass procedure has been advocated in an attempt of increase the hemodynamic support to the territory at risk.

Since Yasargil's description of his first cases of the bypass between the superficial temporal artery and the middle cerebral artery ${ }^{6}$, this became an important adjunct to the management of the ICA sacrifice. Although the use of saphenous vein as a larger conduit, instead of the EC-IC bypass using superficial temporal artery, has being increasingly used ${ }^{7,8}$ it remains to be proven if it is safer and how should the decision be made regarding which type of bypass should be selected ${ }^{9}$. Cerebral perfusion tests, like SPECT, could be one of the parameters to be considered in the decision-making process regarding grouping patients in high or low risk for delayed ischemic events.

\section{CASE}

A 35-years-old woman presented with unilateral right frontal headaches associated with progressive decrease in right visual accuity. A CT scan depicted a parasellar mass, with uniform contrast enhancement, in the right cavernous sinus region. Her neurological performance was otherwise normal. A digital carotid angiography showed a giant transitional type carotid cavernous aneurysm (Fig 1).

After medical clearance and informed consent signed up she went for the HUCFF BTO-SPECT protocol, wich included anticoagulation with heparin (5000 UI) during the procedure. A balloon was placed in the petrous carotid artery and inflated untill complete stop of the anterograde flow was assured. Contralateral ICA injection showed a good cross-filling from the left ICA. Cortical veins filled in both hemispheres at the same time. Hypotension challenge was induced with nitroprusside infusion aiming $30 \%$ reduction of the mean arterial pressure in the last $15 \mathrm{~min}$ utes of the test and Serial neurological examination was performed every 2 minutes during 30 minutes.

After first 15 minutes of inflation of the balloon and already during the hypotensive challenge the IV infusion of the $99 \mathrm{mTc}-E C D^{10}$ was completed. She did not presented any neurological symptoms or signs during the test. After the occlusion time, the catheter was withdrawn and she was sent for the SPECT imaging at the Nuclear Medicine Service. Despite the patient being asymptomatic during the occlusion time, the SPECT images showed an hypoperfusion " infarct-like" image on the right middle cerebral territory (Fig 2).

Based on the results of the test and considering the threat of future ischemic events, particularly in a young patient, it was decided for the high flow saphenous vein bypass between the right cervical carotid artery and the middle cerebral artery. During the operation, there was an atherosclerotic " bleb" already intradural, passing through the elevated parasellar dura (aneurysm mass), confirming angiographic impression of transicional-type of carotid cavernous aneurysm. We proceeded with anastomose of a saphenous vein segment to the cervical ICA and, distally, to the middle cerebral artery, with cerebral protection during the procedure.. After verifying good bypass flow, the cavernous segment of the ICA was defi- 


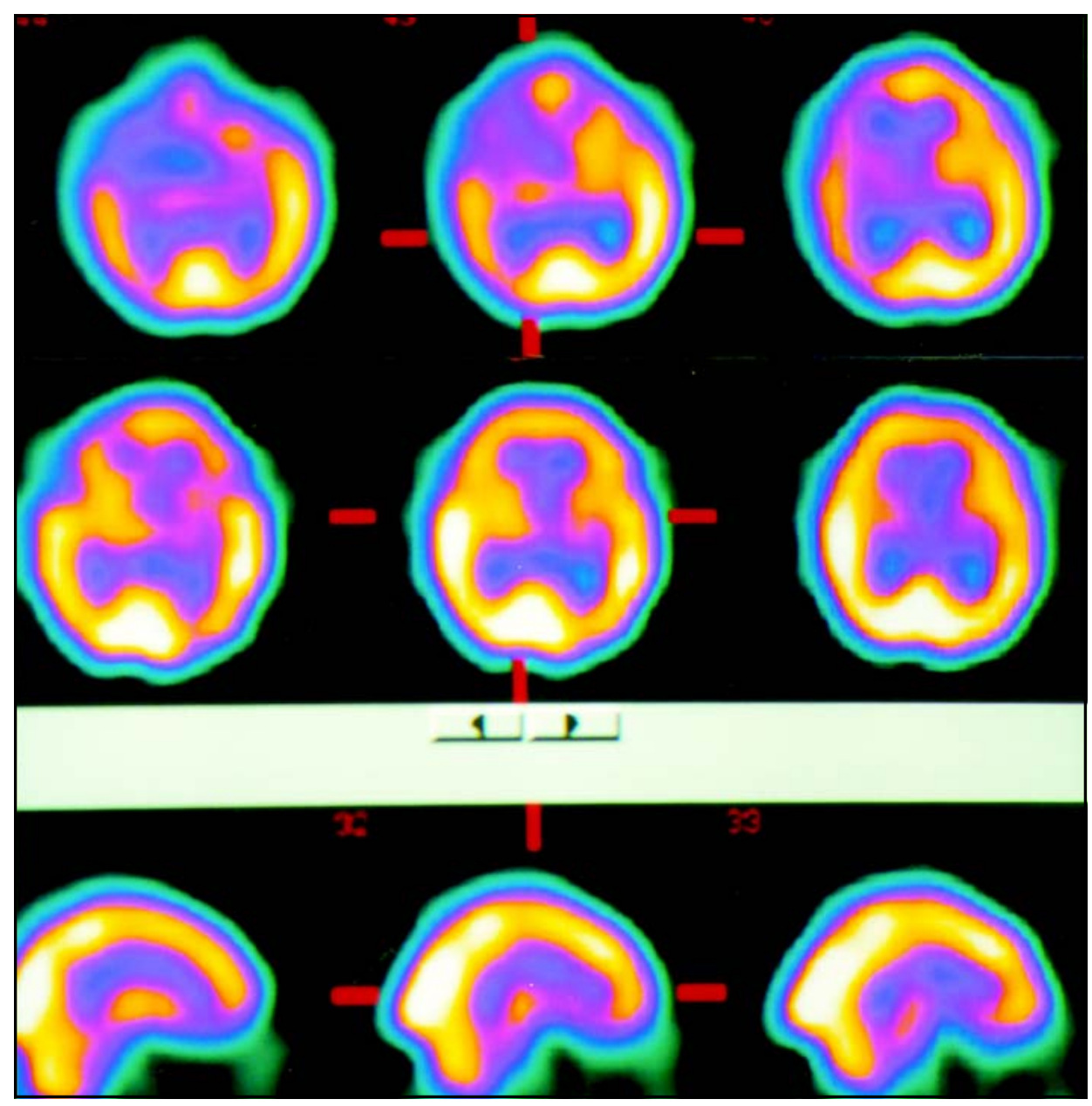

Fig 2. SPECT images during BOT with hypotensive challenge. Clear asymmetry with major hypoperfusion in the right middle cerebral territory.

nitely trapped by ligating its cervical portion and clipping the intracranial one just distal to the aneurysm. Trapping of the aneurysm with complete isolation from the circulation will decrease the chance of rupture by backward flow and will enhance the bypass patency by interruption of the competitive ICA continued perfusion. Postoperativelly she was maintained euvolemic and under aspirin therapy.
Bypass pulse palpation is usually difficult due to postoperative soft tissue edema. A transcranial doppler confirmed the shunt patency. CT showed the aneurysm thrombosis and no evidence of ischemic changes in the area of the middle cerebral trapping for the anastomose. Follow up angiogram showed bypass patency (Fig $3 \mathrm{~A}$ and $\mathrm{B}$ ).

The $99 \mathrm{mTc}-\mathrm{ECD}$ SPECT image after the bypass and ca-
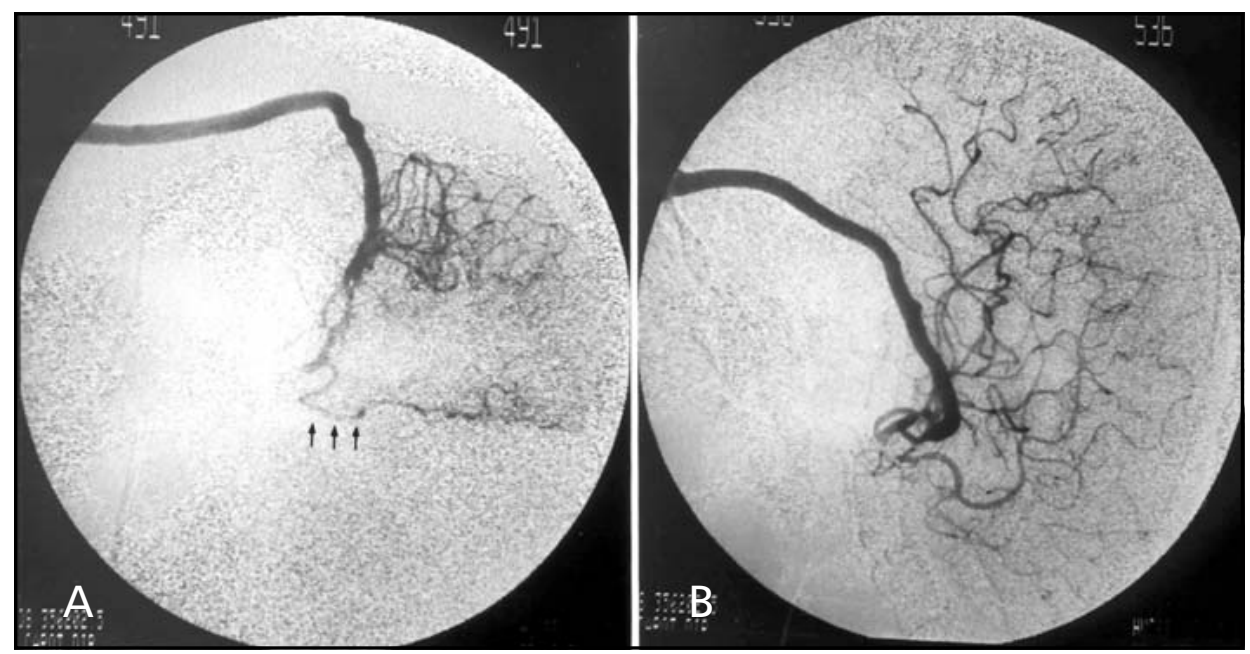

Fig 3. A. Frontal view of the high flow venous channel to the right middle cerebral artery.Arrows pointing to the anterior cerebral vessels perfusion. B. Lateral view of the bypass depicting the flow to the entire right cerebral hemisphere. 


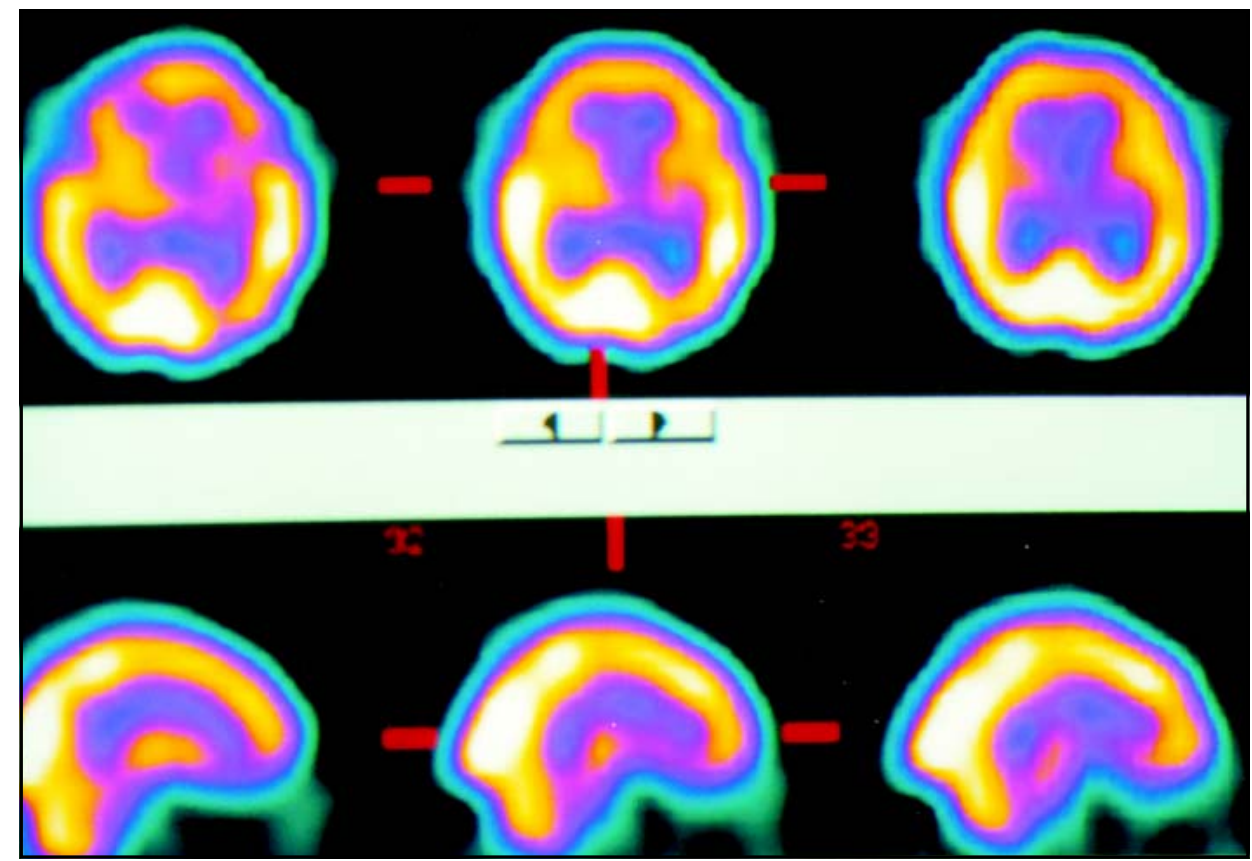

Fig 4. Reversal of the asymmetric perfusion on the SPECT imaging after the bypass. rotid occlusion showed clear perfusion symmetry of the CBF (Fig 4). The patient is asymptomatic and with good flow in the graft one year after the ICA occlusion .

\section{DISCUSSION}

The balloon occlusion test associated to either quantitative or qualitative adjunctive assesment of the carotid reserve followed by therapeutic definitive occlusion is safe and effective treatment for sellected lesions involving the internal carotid artery. The xenon-CT is very popular in many neurosurgical centers due to its assimilation in CT scanners without major expenses, accurate quantitative assesment of the blood flow and easy interpretation. Disadvantages include its anesthetic properties, the "flow activation phenomenon" that induces artefacts in the images and difficulties in the CBF quantification. There is also the risk associated to the transportation of the patient to the $\mathrm{CT}$ suite with the balloon occluding the ICA.

Transcranial doppler imaging has been reported during balloon occlusion test. In a recent study, Eckert et al. reported that TCD was predictive of delayed ischemia due to hemodynamic compromise ${ }^{11}$. SPECT imaging is an acceptable adjunct and, differently the xenon-CT, is capable of asses the CBF after the test is completed.The first pass uptake properties of the SPECT imaging will show up the CBF at the time of the occlusion associated to the hypotensive challenge.We ellected the SPECT as adjunct in our protocol because of its advantages and ready accessibility in our Institution.
Mathis et al. ${ }^{12}$ reported 500 cases of BTO with only $3.2 \%$ complications rate, being $1.2 \%$ transient and $0.4 \%$ permanent neurological deficits. Few studies have demonstrated the long term risk for delayed stroke.Link, Tomsick and Tew reported balloon occlusion of the ICA for unclipable aneurysms between 1978 and 1997, with sixty patients surviving at least 6 months. Four delayed infarcts ocurred at $6,24,30$ and 60 months after occlusion ${ }^{13}$. Fox et al. ${ }^{14}$ described a series of 68 patients treated with proximal carotid occlusion with detachable balloons and an incidence of $13.2 \%$ of delayed ischemic complications. Dare et al. ${ }^{15}$ also had two patients with delayed ischemic complications in spite of early clinical tolerance to BTO test with hypotensive challenge. Both of them showed severe SPECT assymetry during the test. Origitano et al. ${ }^{16}$ reported four delayed ischemic events in 18 patients that underwent permanent ICA occlusion despite negative BTO, during treatment of patients harboring cranial base tumors.

Our case is included in the debate of conflicting directions toward the controversy of prophylactic bypass surgery when confronted with an adjunctive CBF assesment that depicts clear compromise of the collateral circulation. Centers with well known expertise in cerebrovascular surgery have recommended the EC-IC bypass in all patients with indication of therapeutic carotid occlusion because of the future complications of the procedure ${ }^{17}$. Schmiedek et al. ${ }^{18}$ have even demonstrated significant improvement of the cerebrovascular reserve capacity using $\mathrm{Xe}-\mathrm{CT}$ associated to the acetazolamide challenge 
after bypass surgery in patients with recurring cerebral ischemia due to ICA occlusion. Although the EC-IC bypass procedures are not devoid of complications $^{9}$ the literature shows a recent trend toward the use of venous " high flow" conduits, with the flow rate close to the normal at the middle cerebral artery, and an observed higher rate of long term patency ${ }^{8,19}$.

In conclusion, the SPECT images after high flow bypass and carotid sacrifice showing the hemispheric improvement of the perfusion in our patient contributes to the recent trend toward protection from late hemodynamic cerebral infarction in this setting. Cerebral revascularization and parent artery occlusion (trapping) should be seriously considered in patients harboring cavernous carotid aneurysms that are impossible to be clipped, and failed the BTOSPECTtest by developing acute neurological symptoms or having severe CBF compromise.

\section{REFERENCES}

1. Nemzek WR. Carotid artery assesment and interventional radiological procedures before skull base surgery. In Donald PJ (ed). Surgery of the skull base. Philadelphia: Lippincott-Raven 1998;105-118.

2. Lee S, Awad IA. Therapeutic carotid occlusion: current management paradigms. In Grady MS (ed). Clinical neurosurgery: proceedings of the Congress of Neurological Surgeons, Seattle: Lippincott Williams \& Wilkins, 1998;363-391.

3. Standard S, Ahuja A, Guterman L, et al. Balloon test occlusion of the internal carotid artery with hypotensive challenge. Am J Neuroradiol 1995;16:1453-1458.

4. Peterman S, Taylor A, Hoffman J. Improved detection of cerebral hypoperfusion with internal carotid balloon test occlusion and $99 \mathrm{~m}$ TC-HMPAO SPECT imaging. Am J Neuroradiol 1991;13:1035-1041.

5. Yonas $\mathrm{H}$, Linskey $\mathrm{M}$, Johnson $\mathrm{D}$, et al. Internal carotid artery balloon occlusion test does require quantitative CBF. Am J Neuroradiol 1992;13:1147-1152.
6. Yasargil MG, Krayenbuhl HA, Jacobson JH. Microsurgical arterial reconstruction.Surgery 1970;67:221-233.

7. Sundt TM Jr, Piepgras DG, Marsh R, Fode NC. Saphenous vein bypass for giant aneurysms and intracranial occlusive disease. J Neurosurg 1986;65:439-450.

8. Sekhar LN, Bucur SD, Bank WO, Wright DC. Venous and arterial bypass grafts for difficult tumors, aneurysms and occlusive vascular lesions: evolution of surgical treatment and improved graft results. Neurosurgery 1999;44:1207-1224.

9. Abruzzo T, Joseph GJ, Owens DS, Dawson III RC, Reid J, Barrow DL. Prevention of complications resulting from endovascular carotid sacrifice: a retrospective assesment Neurosurgery 2000;46:910-917.

10. Shishido F, Uemura K, Inugami A, et al. Discrepant $99 \mathrm{mTc}-\mathrm{ECD}$ images of CBF in patients with subacute cerebral infarction: a comparison of CBF, CMRO2 amd 99mTc-HMPAO imaging. Ann Nucl Med 1995;9:161-166.

11. Eckert B. Thie A, Carvajal M, Groden C, Zeumer H. Predicting hemodynamic ischemia by transcranial Doppler monitoring during therapeutic balloon occlusion of the internal carotid artery. Am J Neuroradiol 1998;19:577-582.

12. Mathis JM, Barr JD, Jungreis CA, et al. Temporary balloon test occlusion of the internal carotid artery: experience in 500 cases.AJNR Am J Neuroradiol, 1995;16:749-754.

13. Link JM, Tomsick TA, Tew JM. Honored guest presentation: therapeutic carotid occlusion. In Grady MS (ed). Cinical Neurosurgery: proceedings of the Congress of Neurological Surgeons. Seattle: Lippincott Williams \& Wilkins 1998;326-338

14. Fox AJ, Vinuela F, Pelz DM, et al. Use of detachable balloons for proximal artery occllusion in the treatment unclippable cerebral aneurysms. J Neurosurgry 1987;66:40-46.

15. Dare AO, Chaloupka JC, Putman CM, Fayad PB, Awad IA. Failure of the provocative test during balloon test occlusion of the internal carotid artery to predict delayed hemodynamic ischemia after therapeutic carotid occlusion. Surg Neurol 1998;50:155-156.

16. Origitano TC, Al-Mefty O, Leonetti JP, DeMonte F, Reichman HO. Vascular considerations and complications in cranial base surgery: clinical study. Neurosurgery 1994;35:351-363.

17. Lawton NT, Hamilton MG, Morcos JJ, Spetzler RF. Revascularization and aneurysm surgery: Current techniques, indications and outcome. Neurosurgery 1996;38:83-94.

18. Schmiedek P, Piepgras A, Leinsinger G, Kirsch C-M, Einhaupl K. Improvement of cerebrovascular reserve capacity by EC-IC arterial bypass surgery in patients with ICA occlusion and hemodynamic ischemia.J Neurosurg 1994;81:236-244.

19. Tedeschi H, Castro JM, Ferreira MAT, Wen HT, de Oliveira E. Aspectos técnicos e resultados do bypass de alto fluxo com veia safena para aneurismas complexos.J Bras Neurocirurg 1999;10:5-14. 